2020-5

\title{
Established Adulthood: A New Conception of Ages 30 to 45
}

Clare M. Mehta

Emmanuel College - Boston

Jeffrey Jensen Arnett

Clark University

Carlie G. Palmer

Brigham Young University - Provo

Larry J. Nelson

Brigham Young University - Provo, larry_nelson@byu.edu

Follow this and additional works at: https://scholarsarchive.byu.edu/facpub

Part of the Other Social and Behavioral Sciences Commons

\section{Original Publication Citation}

Mehta, C., Arnett, J. J., Palmer, C. G., \& Nelson, L. J. (2020). Established Adulthood: A New

Conception of Ages 30 to 45. American Psychologist, 75, 431-444. doi.org/10.1037/ amp0000600

\section{BYU ScholarsArchive Citation}

Mehta, Clare M.; Arnett, Jeffrey Jensen; Palmer, Carlie G.; and Nelson, Larry J., "Established Adulthood: A New Conception of Ages 30 to 45" (2020). Faculty Publications. 4710.

https://scholarsarchive. byu.edu/facpub/4710

This Peer-Reviewed Article is brought to you for free and open access by BYU ScholarsArchive. It has been accepted for inclusion in Faculty Publications by an authorized administrator of BYU ScholarsArchive. For more information, please contact ellen_amatangelo@byu.edu. 


\title{
Established Adulthood: A New Conception of Ages 30 to 45
}

\author{
Clare M. Mehta \\ Emmanuel College and Boston Children's Hospital, Boston, \\ Massachusetts \\ Carlie G. Palmer and Larry J. Nelson \\ Brigham Young University
}

Jeffrey Jensen Arnett Clark University

\begin{abstract}
In developed countries, the years from Age 30 to 45 are, for many, the most intense, demanding, and rewarding years of adult life. During this period of the life span most adults must negotiate the intersecting demands of progressing in a chosen career, maintaining an intimate partnership, and caring for children. Successes or difficulties in meeting these simultaneous demands have the potential to profoundly influence the direction of a person's adult life. As such, we believe that it is of critical importance to better understand this developmental period that we call established adulthood. This article provides a new theoretical conceptualization of established adulthood, outlining its distinctiveness from emerging adulthood and midlife in terms of physical health, well-being, cognitive development, and the career-and-care-crunch of competing work and family responsibilities. We also consider variations in the timing and experience of established adulthood, including variations by gender and social class, and provide suggestions for future research. As economic and social arrangements continue to evolve, so too will this developmental period, providing fertile ground for developmental theory and research.
\end{abstract}

\section{Public Significance Statement}

This article provides a new theoretical conceptualization of established adulthood, the period from 30-45. The article distinguishes established adulthood from emerging adulthood and midlife in terms of physical health, well-being, cognitive development, and the career-and-care-crunch of competing work and family responsibilities. Because successes or difficulties in handling the intensity of the intersection of work and family demands have the potential to profoundly influence the direction of a person's adult life, a better understanding of this developmental period may promote policy, programs, or therapeutic interventions to support established adults as they navigate what may be one of the most intense and demanding periods of the life span.

Keywords: adulthood, work-life balance, developmental theory, lifespan development, psychosocial development

Over the past several decades, psychological theory and research has made substantial progress in charting most

Editor's note. This article is part of a special issue, "Rethinking Adult Development: New Ideas for New Times," published in the May-June 2020 issue of American Psychologist. Jeffrey Jensen Arnett, Margie E. Lachman, and Oliver Robinson served as guest editors of the special issue with Nancy Eisenberg as advisory editor. Nancy Eisenberg served as the action editor for this article.

Authors' note. (D) Clare M. Mehta, Department of Psychology, Emmanuel College, and Division for Adolescent Medicine, Boston Children's Hospital, Boston, Massachusetts; Jeffrey Jensen Arnett, Department of Psychology, Clark University; Carlie G. Palmer and Larry J. Nelson, Department of Family Life, Brigham Young University.

Correspondence concerning this article should be addressed to Clare M. Mehta, Department of Psychology, Emmanuel College, 400 the Fenway, Boston, MA 02115. E-mail: mehtac@emmanuel.edu segments of the adult life span. The theory of emerging adulthood focused on how the years from Age 18 to 29 have changed across developed countries and conceptualized these years as a new life stage (Arnett, 2000, 2015). The landmark Midlife in the United States (MIDUS) longitudinal study explored features of midlife in the United States and in Japan, generating new interest in the distinctive characteristics of Ages 45 to 65 (Brim, Ryff, \& Kessler, 2004; Ryff et al., 2008), and theoretical work has highlighted midlife as a crossroads between growth and decline (Lachman, Teshale, \& Agrigoroaei, 2015). Finally, worldwide societal recognition of the consequences of steadily increasing longevity has led to growing theoretical and research attention to the later years of adulthood (Kunkel, Brown, \& Whittington, 2014).

Despite an increased focus on adulthood in psychological science, one period of the adult life span has been largely 


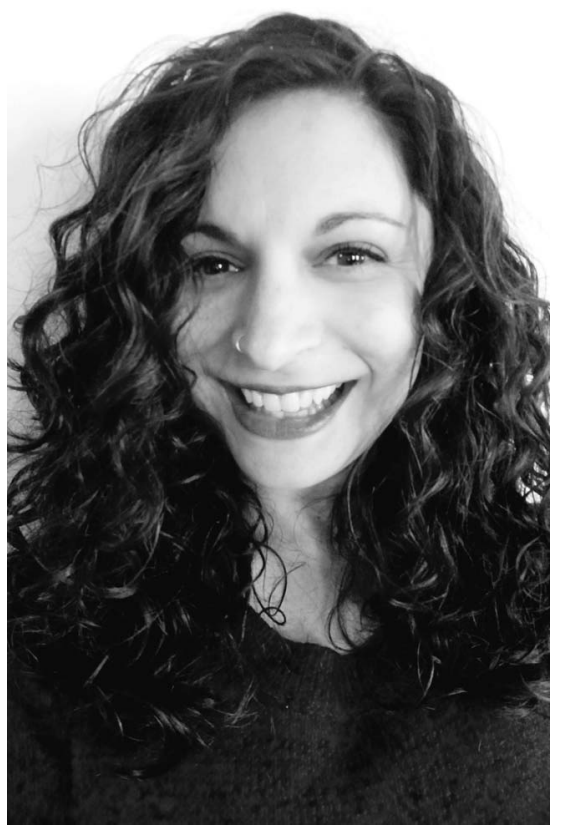

\section{Clare M. Mehta}

overlooked. This is the period from Age 30 to 45, when most people are deeply absorbed in career development while fulfilling the responsibilities of an intimate partnership and caring for children. Although there is abundant research on key aspects of this developmental phase, including career development, marital satisfaction, divorce, and parenting, these aspects of development have not been integrated into a compelling developmental theory. Hence, the purpose of this article is to provide a new conceptualization of the years from roughly Age 30 to 45 . We propose to call this developmental period established adulthood.

There are a number of reasons why a comprehensive developmental theory of established adulthood is needed. First, there is no current common nomenclature for this period of the life span. It is sometimes referred to as part of "young adulthood," but that term has been applied as young as Age 18 and as old as Age 45 (Arnett, 2015). It is sometimes referred to as part of "middle adulthood," but midlife theory and research more often focuses on Ages 40 or 45 to 60 and can extend as high as Age 65 (Lachman, 2004; Lachman et al., 2015). Without an agreed upon term for the period after emerging adulthood but before midlife, it is hard to compile the research base necessary to gain a comprehensive understanding of it. Second, we believe that it is imperative to build a developmental theory of this period because the years from 30 to 45 are often the most intense and demanding years of adult life in developed countries, when obligations are high in both work and family domains. Moreover, successes or difficulties in handling the intensity of the intersection of these developmental tasks has the potential to influence profoundly the rest of a person's adult life. Consequently, a better understanding of this developmental period has implications for supporting established adults through policy or therapeutic interventions, as they navigate what has been described as the "rush hour of life" (Knecht \& Freund, 2016).

In proposing the concept of established adulthood, we first examine its theoretical place in the life span. We then examine how established adulthood is distinct from emerging adulthood and midlife in terms of physical health, wellbeing, and cognitive development. Next, we focus on the intersection of work and family responsibilities during Ages 30 to 45 as the central developmental challenge of these years. We then consider variations in the timing and experience of established adulthood, including variations by gender, ethnicity, and socioeconomic status (SES), as well as other variations, such as having children early or remaining single without children. Finally, in the last section of the article, we propose some initial research questions.

From the outset, it should be noted that due to space limitations we are unable to describe all aspects of this new conceptualization of Ages 30 to 45, and we focus mainly on developed countries. Space limitations have also led us to focus on salient developmental tasks. As development is dynamic and not static, it is important to remember that these tasks represent developmental processes. For example, becoming a parent is not a single life event, but an ongoing developmental process during which identity, behavior, and interactions with a person's immediate (e.g., the workplace) and distal (e.g., larger social structures) contexts evolve. We are also limited to building our theory by reviewing extant research that, like most psychological research, has been conducted mainly with samples that are predominantly White, middle class, and Western (Arnett, 2008). Race, ethnicity, gender, social class, and cultural context are likely to be hugely influential in people's experiences of established adulthood and should be a focus of research in the new field.

\section{Phase, Period, Conception, or Life Stage?}

Is established adulthood a phase, period, conception, or life stage? For decades there has been a lively debate in developmental psychology over the usefulness of life stage concepts (Arnett, 2016; Elder \& Shanahan, 2006). Until this debate was initiated in the 1980s, psychology had a long and unfortunate history of proposing universal life stage theories based on a tiny segment of the human population. Critics rightly called the assumptions of those theories into question. We hope that psychology has now decisively moved beyond universal assumptions and that there is widespread recognition that the historical and cultural context of human development is of crucial importance across the life span (Jensen, 2015). We are certainly not proposing established adulthood as a universal, one-size-fits-all theory. We acknowledge that many may not experience established adult- 




Jeffrey Jensen Arnett

hood as we outline it here. Rather, we are proposing established adulthood as a potentially useful heuristic for conceptualizing a fascinating and important period of adult development that has either been neglected or combined with other periods of the life span in developmental research.

We view life stage concepts as cultural constructions that provide a useful map of culturally expected developmental risks and challenges in each portion of the life span (Arnett, 2016). Developmental change in adulthood is continuous rather than separated into phases, and does not occur within strict time frames as it does in childhood and adolescence (Hoare, 2006; Hooker, 2015). This is because during adulthood sociocultural processes have a greater influence on development than biological processes or institutional structures such as schools (Baltes, 1987; Hooker, 2015). This means that variations in our contexts, experiences, life choices, and social roles lead us to become more, not less, heterogenous as we age (Hoare, 2006). Consequently, the age range of 30 to 45 for the period of established adulthood is approximate, and is likely to vary by race, ethnicity, SES, culture, country, developmental contexts, individual choices, and historical context. These factors are also likely to influence people's experience of established adulthood. While we outline here some of the developmental tasks and concerns that we believe are salient for those in this age period, we acknowledge that these tasks will not be relevant to all groups of people. Specifically, not all people will experience the normative route through established adulthood as we outline it here. We hope that researchers will investigate this period of development to document its many variations.
It should also be noted that the specific term "life stage" has a long history in developmental psychology, usually denoting qualitative change from one stage to another, for example from concrete to formal operations in Piagetian theory. That is not how we are using life stage here; we see life stages simply as conceptual frameworks that may or may not entail qualitative change but are useful ways of delineating the main developmental issues and challenges of each phase of life. However, for those who prefer a more restrictive use of life stage, established adulthood might not meet the requirements to be a developmental stage and may thus be better viewed as a phase of adult development.

In this spirit, and with these caveats, we believe that proposing established adulthood as a new concept has the potential to clarify the developmental issues and processes prominent during the years 30 to 45 and draw together the large but disconnected body of research that has focused on topics such as parenting young children, career development, and work-family balance. We also hope that proposing this new life stage concept will inspire research focused specifically on the experiences of those Aged 30-45. Our model is the theory of emerging adulthood, which drew together existing literature on topics such as the school-towork transition and leaving the parental home and has inspired thousands of studies on Ages 18-29 since it was proposed 20 years ago (Arnett, 2000). We hope that proposing an integrated developmental conception of established adulthood will have a comparable effect of inspiring research on development at Ages 30 to 45 .

\section{Distinction Between Emerging and Established Adulthood}

Although an adult life phase of family formation and career development was recognized by early developmental theorists such as Havighurst (1953) and Levinson (Levinson, Darrow, Klein, Levinson, \& McKee, 1978), a number of important demographic changes have taken place over the past half century that have shaped the current structure of established adulthood, making it demographically distinct from emerging adulthood and situating it roughly in the age period of 30 to 45 . In developed countries, work and family life transitions that historically took place when people first reached their twenties are now typically taking place when people reach their thirties (Arnett, 2015). Across developed countries, more people are obtaining tertiary education or training well into their twenties, and finishing education is typically followed not by entry into a stable long-term job but by years of frequent job changes with commitment to a career not occurring until the thirties. For example, in the United States the median number of job changes from Age 18 to 29 is 10, a far higher number than in any subsequent decade (Bureau of Labor Statistics, 2019a; United States Department of Labor, 2019). Addi- 




tionally, in contrast to the high rates of unemployment in the twenties, by Age 30 unemployment falls to a stable rate maintained through the forties and fifties, across developed countries (Organisation for Economic Co-operation and Development [OECD], 2019b). In sum, in contrast to the exploration, information gathering, and career preparation that typically takes place during emerging adulthood, established adults tend to commit to an occupational path that includes gaining greater expertise, taking on greater responsibilities, and moving up in an organizational hierarchy (Day, Harrison, \& Halpin, 2012).

While this pattern of career development is common, it is important to note that there are likely to be exceptions based on race, ethnicity, gender, and social class. Longstanding structural and systemic racism across Western countries often impedes the career development of people of color (American Psychological Association, 2007). For example, in the United States people of color are disproportionately unemployed, underemployed, and in precarious, low paying jobs (Bureau of Labor Statistics, 2011, 2019b). This means that during established adulthood, while most of their White counterparts are enjoying stability and advancement in their careers, people of color may continue to experience career instability and stagnation (Doede, 2016).

In the family domain as well, there has been a normative upward age shift toward commitment and stability occurring around Age 30. Across developed countries the median age of first marriage is higher than ever before, around Age 30 for women and 32 for men (OECD, 2019c). Most developing countries are trending in the same direction. Similar shifts have taken place internationally in the median age of first childbirth, which is also now around 30 for women in developed countries and is rising in developing countries (OECD, 2019a). Between 2000 and 2014, the proportion of first births to women in developed countries Aged 30-34 rose 28\% and first births to women Aged 35 and over rose $23 \%$, whereas births among younger women declined (OECD Family Database, 2018).

In the family as in the work domain, demands are likely to vary by race, ethnicity, and socioeconomic background. For instance, Latinx and African American women have lower median ages of first childbirth than Whites and Asian Americans (Mathews \& Hamilton, 2016), and are more likely to be single mothers (Hummer \& Hamilton, 2010). The stresses of established adulthood may therefore be compounded in these groups.

\section{Distinction Between Established Adulthood and Midlife}

In contrast to the early theories of Havighurst (1953) and Levinson (Levinson et al., 1978), little modern theory has distinguished between established adulthood and midlife. Instead, the years of middle adulthood have been often stretched to extend from as low as Age 30 to as high as Age 65 (Lachman, 2004; Lachman et al., 2015). However, we believe that range is too large to be developmentally meaningful and that it is more coherent and compelling to distinguish established adulthood (roughly Ages 30-45) from middle adulthood (roughly Ages 45-65).

Established adulthood is developmentally distinct from midlife in a number of ways. Established adults are typically gaining expertise in their chosen field and seeking to rise in their work status and achievements, whereas most midlife adults have reached the peak of their career arc (Riza, Ganzach, \& Liu, 2018). Established adults often have young children who are living at home and a large part of their daily lives is devoted to caring for those children. In contrast, adults at midlife more often have older children, who have left the family home or, if still at home, require less physically demanding care from parents. Midlife adults are also more likely than established adults to experience agerelated physiological changes, such as menopause for women and andropause for men.

\section{Notable Features of Established Adulthood}

Like other developmental phases, established adulthood has distinctive features that are more prominent during this period than during other periods of life. Table 1 summarizes a range of distinctive features of established adulthood as compared to emerging adulthood and midlife. Below, to illustrate the utility of viewing established adulthood as a separate phase of the adult life span, we briefly summarize the distinctiveness of the years from 30 to 45 in terms of physical health, well-being, and cognitive development, and 


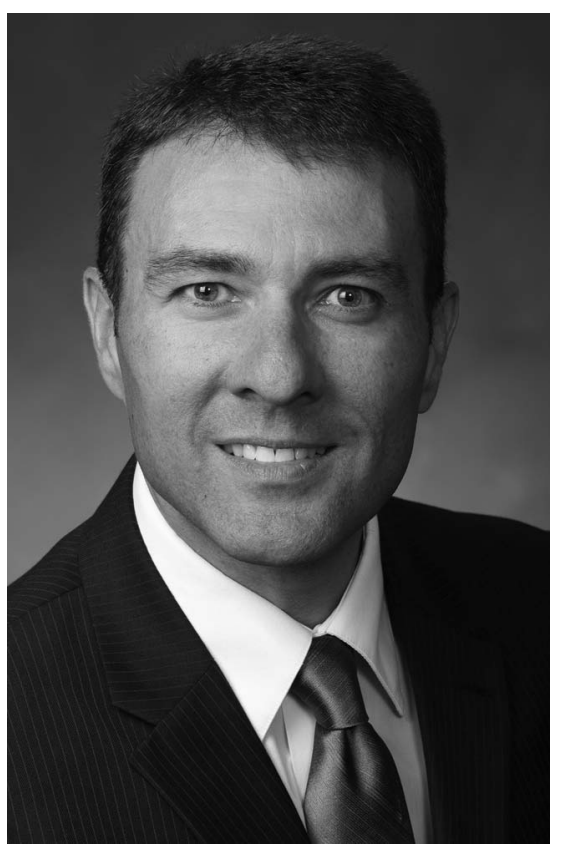

Larry J. Nelson

then highlight the collision of developmental tasks in the work and family domains.

\section{Physical Health and Well-Being}

Physical strength and stamina generally decline after the twenties. By the early thirties, the peak of athletic performance has passed, and it takes longer to recover from injuries than in the twenties (Bruner, Erickson, Wilson, \& Côté, 2010; Houglum, 2010). Primary aging leads to declines in the basal metabolic rate, and because fewer calories are burned when a person is resting, weight gain and obesity increase (Peitilainen et al., 2008). Nevertheless, most people experience good physical functioning during established adulthood, and the years from Age 30 to 45 are, in some respects, the physically healthiest of the entire life span. During these years the immune system is strong and susceptibility to most infectious diseases is low. Established adults are not yet at risk for the types of diseases that commonly occur in middle and later adulthood, most notably cancer and heart disease. Furthermore, established adults have healthier eating and sleeping patterns than emerging adults (Braveman, Egerter, \& Williams, 2011) and are far less likely to engage in risky behaviors that may endanger health, including risky driving, substance use, and risky sexual behavior (Arnett, 2015).

The literature on well-being across the adult life span is complex and difficult to interpret (Arnett, 2018). Probably the best data come from the MIDUS study, which surveyed a national sample of adults Ages 25-74 in the United States on multiple domains of life satisfaction, including marriage, work, relationships with children, and finances (Lachman,
2004; Lachman et al., 2015). While overall life satisfaction was more or less flat across age groups, each domain showed a different pattern of change with age. During the age period of 30-45, satisfaction was highest in the domains of marriage and relationships with children and lowest for finances and sexuality. In 10-year longitudinal data from the study, positive affect was lower across Ages 25-39 than at Ages 50 and above. However, emerging and established adults were both more optimistic about the future than their elders were; expected future life satisfaction was highest at Ages 25-39 and fell steadily after age 40. More research is needed to better understand trajectories of health and well-being in established adulthood across countries and cultures.

\section{Cognitive Development}

In many ways, cognitive development is enhanced during established adulthood. The landmark Seattle Longitudinal Study showed that intelligence rises through the thirties and early forties in nearly all domains, including spatial orientation, inductive reasoning, and verbal ability (Schaie, 2013). The one exception is perceptual speed, an aspect of fluid intelligence that declines steadily from the midtwenties onward.

Established adulthood is also the period when expertiseextensive knowledge and skills in a specific field-is most likely to be reached (Chi, Glaser, \& Farr, 2014). This is because it takes about 10 years of study or practice in a field to attain expertise, and most people begin steady work in a specific field in their twenties. The development of expertise in established adulthood is not confined to high-SES fields. A study of food-services workers found that expertise-defined in terms of knowledge (of menu items and food presentation); organizational skills (such as handling orders efficiently); and social skills (such as confidence in interacting with customers)-increased from the 20s to the 30s and 40s (Perlmutter, Kaplan, \& Nyquist, 1990). Attaining expertise enables people to move from problem solving to problem finding, as they use their acquired knowledge and skills to think in new ways $(\mathrm{Hu}$, Shi, Han, Wang, \& Adey, 2010).

Because creativity requires a base of expertise, its peak comes only after expertise has been sufficiently developed, usually in the thirties. Consequently, during established adulthood, creativity has the potential to flourish as established adults are able to combine expertise with openness to new ideas, tolerance for ambiguity, and a willingness to take intellectual risks (Sternberg, 2018). A number of studies of people with exceptional accomplishments have found that their creative achievements rise during established adulthood and peak in the late thirties or early forties, then gradually decline through middle and late adulthood (Simonton, 2010). Even though expertise continues to rise 
Table 1

Distinctive Features of Established Adulthood in Comparison to Emerging Adulthood and Midlife

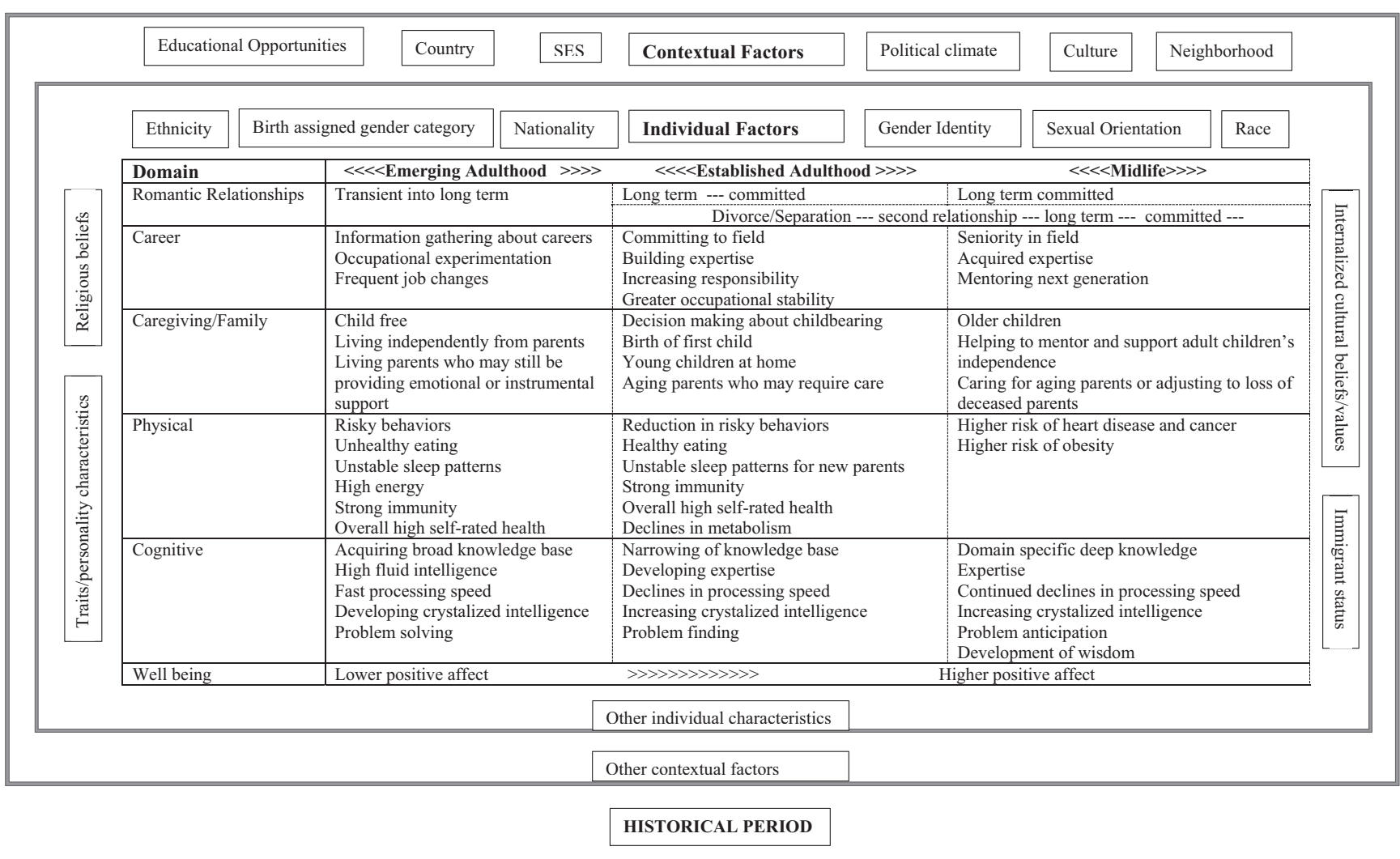

Note. $\quad$ SES $=$ socioeconomic status.

through middle adulthood and beyond, "familiarity breeds rigidity" (Mednick, 1963), and beyond established adulthood, expertise tends to steer people down the same cognitive paths rather than inspiring creative new ideas.

\section{The "Career-and-Care-Crunch": The Developmental Challenge at the Heart of Established Adulthood}

In all societies, work and family are the two main domains of adult life. Work and family are varyingly defined. "Work" may be inside or outside of the home. "Family" may entail marriage and caring for children, caring for children outside of marriage, marrying but not having children, remaining unmarried and serving as a devoted aunt or uncle, or serving as a caretaker for aging parents. Across the forms that work and family may take, contemporary adulthood brings a pile-up of demands from Age 30 to 45 as people pursue multiple work and family goals simultaneously. While some goals may be interdependent such that success in one domain facilitates success in others (e.g., securing a good job may generate resources to provide for children), others may be incompatible, placing competing demands on insufficiently available resources (e.g., working toward advancement at work may reduce time with family; Riediger, Freund, \& Baltes, 2005).

Important changes in work and family demands that have occurred in recent decades have led to this pile up of demands and competing goals during the 30s and 40s. We believe that this merits recognition, and it is part of the impetus for conceptualizing a theory of established adulthood. To summarize the demographic patterns presented earlier: The 20s are often devoted to obtaining education and sampling occupational paths before making an occupational commitment at around Age 30. First marriages also typically take place around Age 30, and couples often feel a need, desire, and obligation to spend time together in order to develop a solid relational foundation for the future (Cherlin, 2010). The birth of the first child also takes place around Age 30 across developed countries. Consequently, established adulthood brings a simultaneous collision of demands, goals, and aspirations as people attempt to progress at work and achieve a deep level of intimacy in a long-term 
romantic relationship while also responding to the relentless demands of caring for one or more young children. We call this the career-and-care-crunch.

The competing demands of work and family for adults have long been studied as work-family balance or workfamily conflict (e.g., Wayne, Butts, Casper, \& Allen, 2017).

This literature generally supports the idea proffered here: that conflicts between demands of work and family increase from the twenties to the thirties and forties and then decline in later decades (Huffman, Culbertson, Henning, \& Goh, 2013). Consequently, during this period people must adjust the extent to which they engage in boundary management, separating or integrating the boundaries between their work and home life (Kossek, Lautsch, \& Eaton, 2006).

We propose the new term career-and-care-crunch to draw attention to our theoretical proposal that the crunch peaks in established adulthood. As part of this conception, we recognize that the psychosocial demands entailed may go beyond child care and include relations with parents, friends, community organizations, and even pets. Furthermore, our crunch concept highlights that the conflict at Ages $30-45$ is not just between work and family domains but between multiple demands within the family domain. The term also underscores that the intersecting demands at this age period often require something to be sacrificed and people may find themselves feeling like they are coming up short in work or family or both. Consequently, we believe that these competing demands are best described as a crunch.

\section{Romantic Partnerships and the Crunch}

The impact of the crunch is perhaps most evident in research on established adults' long term romantic relationships, typically marriage. The period following entry to marriage tends to be high in terms of happiness and marital satisfaction, and newlywed couples often behave in ways consistent with idealized conceptions of the soul-mate marriage by downplaying negative feelings, avoiding conflict, and highlighting the positive characteristics of their partner and their relationship (Cherlin, 2010; Huston, Caughlin, Houts, Smith, \& George, 2001). During this period couples spend a good deal of time together, as they work to establish marital intimacy.

When long-term romantic partners become parents, however, additional strain is placed on the intimate partnership. The transition to parenthood, lasting from conception until the child is 1 year of age, is a major life-altering change (Fillo, Simpson, Rholes, \& Kohn, 2015; Goldberg, 2010; Sheedy \& Gambrel, 2019; Young, Roberts, \& Ward, 2019). The birth of a child requires a romantic partnership comprised of two people to evolve into a three-person family system and requires adults to take on a new role and identity as parent (Goldberg, 2010). While the transition to parent- hood can bring joy and excitement, it also brings challenges and stressors that may leave parents feeling exhausted, overwhelmed, and isolated (Mickelson \& Biehle, 2017; Nazarinia-Roy, Schumm, \& Britt, 2014). New parents must often return to work within a few weeks or months of the birth and abruptly learn to negotiate the competing demands of work and family life (Borelli, Nelson-Coffey, River, Birken, \& Moss-Racusin, 2017). It is no surprise then that new parents typically experience decreases in relationship satisfaction and intimacy, which may increase relationship conflict (Mickelson \& Biehle, 2017). Furthermore, divorce risk rises steeply in the early years of parenthood (Gottman, 2014). In sum, the crunch entails not just a conflict between work and family demands but a conflict within the family between the demands of child care and the demands of maintaining an intimate partnership.

\section{A Gendered Crunch: The Harsher Challenge for Women}

A half century after the rise of feminism, gender roles in most developed countries are less sharply defined than previously, and in established adulthood heterosexual couples often share many of the duties that traditionally fell to one gender or the other (Gottman \& Gottman, 2017). Historically, few fathers in developed countries involved themselves in the daily duties of child care. For example, according to national United States data, as recently as 1965 men spent only 10 min per day with their children, compared to $85 \mathrm{~min}$ for women (Cotter \& Pepin, 2017). By 2016, men's time with children had risen substantially, to about 58 min.

Nevertheless, American mothers' time with children-90 min per day in 2016 - remains higher than fathers', and mothers in heterosexual relationships still provide the majority of child care in infancy and beyond (Nazarinia-Roy et al., 2014). This may reflect that women, rather than men, continue to be socialized into caregiving roles from a young age (Fillo et al., 2015). Several studies have found that gender roles in developed countries become more traditional following the birth of the first child (Dew \& Wilcox, 2011; Le, McDaniel, Leavitt, \& Feinberg, 2016). Developed countries vary, but even in the northern European countries, where ideologies of parenting promoting gender equality are strongest, young mothers are far more likely than young fathers to take parental leave and to have the main responsibilities for parenting (OECD, 2018).

Women make a greater contribution not only to child care but to household work in heterosexual couples. The number of hours men spend on housework remains largely unchanged during the transition to parenthood. Women do more housework and childcare than men do even when they make more money than their husbands (OECD, 2019d; Wang, 2019). It is no surprise then that the division of labor 
in childcare and household tasks is often a source of conflict for new parents (Nazarinia-Roy et al., 2014).

A key consequence of the gendered crunch is the "motherhood wage penalty." Women who have children make less money than women in the same profession who do not have children, whereas men experience no comparable penalty and may even experience a wage enhancement compared to men without children (Budig, Misra, \& Boeckmann, 2016). The motherhood penalty is due primarily to leaving the workforce temporarily or reducing employment hours, thus forgoing crucial years of building expertise, and is highest for women with the most education (England, Bearak, Budig, \& Hodges, 2016). Women experience the motherhood penalty across developed countries, although it is smaller in countries that provide high-quality, affordable child care (Cukrowska-Torzewska, 2017).

\section{Social Class and the Crunch: The Special Case of the United States}

In some developed countries, universal social policies such as paid parental leave and government-funded child care reduce class differences in the experience of the crunch (Cukrowska-Torzewska, 2017). However, the United States has the greatest inequalities of wealth of any developed country and the least generous social programs, so many aspects of life, including the crunch, are more deeply influenced by social class (Glass, Simon, \& Andersson, 2016). Specifically, the lower the social class status in the United States, the more likely it is that the crunch will take place early, and alone.

In recent decades, the rise in the median age of first childbirth to around Age 30 has taken place mainly among women in the highest social class, that is, who have a college degree (Hymowitz, Carroll, Wilcox, \& Kaye, 2013). In contrast, among those who have only some college, or a high school diploma or less, median age at first childbirth is only in the mid-20s. Furthermore, a large and growing social class disparity has developed in recent decades in the likelihood that the first birth will take place in the context of marriage. Among young Americans with a college education, only $12 \%$ of first births take place outside of marriage, compared to $58 \%$ for those with a high school diploma or some college and $83 \%$ for those with less than a high school diploma (Hymowitz et al., 2013). Unmarried parents may be cohabiting, but in the United States cohabiting relationships are three times as likely as marital relationships to dissolve within 5 years of the birth of a first child.

The main consequence of an earlier crunch is that the demands of raising children may occur before new parents have had time to finish their education, try different occupational options and establish a definite direction, and develop expertise in their field. The likely result is that longterm career development will be impaired. Similarly, for single parents, the crunch of trying to make occupational progress while caring for a young child is intensified and prospects for success are less promising when there is no partner with whom to share the responsibilities of child and household on a daily basis. The stress of being a single parent is compounded by financial stress; single mothers, in particular, often have low incomes, partly because they have less education (Garrett-Peters \& Burton, 2016). Furthermore, given the many challenges and strains faced by couples in adjusting to and caring for a child, it is not hard to see how difficult it must be for a single parent to handle these challenges primarily alone.

Another distinctive feature of the United States is that social class and ethnicity are deeply intertwined. African Americans and Latinx persons are more likely than people in other ethnic groups to grow up poor and have lower educational attainment. They also have lower median ages of first childbirth than Whites or Asian Americans do, and are more likely to be single mothers. In part because of this, African American and Latina single mothers often receive child care assistance from their own mothers (Taylor \& Conger, 2017). In short, the timing and content of the crunch varies among American ethnic groups, and this variation should be an important focus of research in a new field of established adulthood.

\section{Variations in Established Adulthood}

Although most established adults in developed countries experience the crunch, there are diverse alternative paths through established adulthood. In addition to the variations by gender and social class just described, we briefly describe several other variations here.

\section{Variation 1: The Single Life}

Although the timing of entry to marriage is later than in the past, it remains true that over $80 \%$ of young people in developed countries enter marriage or another committed long-term partnership by their 30s (Fletcher, Simpson, Campbell, \& Overall, 2015). Nevertheless, a substantial proportion of established adults remain unmarried past Age 40. Some may not find a partner with whom they are willing to commit to a long-term relationship (DeLyser, 2012), whereas others may remain "single by choice" (DePaulo, 2006). Generally, health and happiness are high for people who remain single throughout established adulthood. Their life satisfaction is not as high as for happily married people, but it is higher than for established adults who are separated, divorced, or unhappily married (DePaulo, 2012). Rates of established adults who remain single are rising in Asian countries such as Japan and South Korea, apparently due to young women's resistance to the cultural expectations of duty and submission imposed on them following marriage 
and (especially) motherhood (Rosenberger, 2007; Yamada, 2017). Marriage rates are also declining in China due to the imbalance in the ratio of women to men created by years of the one-child policy that favored male children over females (Hudson \& Den Boer, 2002; Nelson \& Chen, 2007). Given the increasing numbers of persons who are single during established adulthood, there is a need to investigate the correlates and outcomes of singlehood in future research, in diverse countries and cultures.

\section{Variation 2: Coupled but No Children}

Another prominent variation in established adulthood is the growing number of people in developed countries who are choosing to remain "child free." While men may occasionally be questioned about the decision to remain child free, sociocultural expectations around childbearing for women and beliefs that motherhood is a central component of the female role mean that women who choose not to have children are often stigmatized and face social exclusion and discrimination (Doyle, Pooley, \& Breen, 2013). In addition, child-free couples are often not regarded as a "family," both socioculturally and in the research literature (Pelton \& Hertlein, 2011). Although more same-gender partners in the past have children, in the United States only about $8 \%$ of male same-gender partners and $24 \%$ of female same-gender partners have one or more children (Goldberg \& Conron, 2018).

It is important to note that while some established adults may be child-free voluntarily, there are others who wish to have children but cannot, for reasons including fertility issues, economic constraints, or reproductive choices based on susceptibility to genetic disease. For many, being involuntarily childless is an emotionally painful experience that entails feelings of shame, grief, and loss (Bell, 2013; Koert \& Daniluk, 2017). Ultimately, however, most couples who do not choose to overcome involuntary childlessness via adoption carve out new and fulfilling adult identities for themselves that do not include parenthood (Pelton \& Hertlein, 2011). Furthermore, their marital satisfaction is higher than for couples with children (Nelson, Kushlev, \& Lyubomirsky, 2014).

\section{Variation 3: One Full-Time Parent}

Although there are more dual-earner couples than ever across developed countries, there are some established adult couples in which one partner works outside of the home while the other works inside the home providing household work and childcare. This arrangement may be due to culturally or religiously based beliefs, to job loss or other economic factors, or may be a response to a trend in developed countries toward "intensive" parenting (Cranney \& Miles, 2017; Sherman, 2009). Regardless of the reason, the crunch may look different for established adult parents where only one person works outside of the home. Specifically, while the working parent may still participate in childcare and housework, some of the stresses associated with the multiple demands of work and home may be reduced as each partner primarily focuses energy and attention in one domain. However, the nonemployed parent gives up crucial years of career progress and expertise-building that will be difficult to make up when reentering the work world (Budig et al., 2016).

\section{Variation 4: No Career, Just a Job}

In a similar vein, it may be that the nature of the crunch is different for established adults whose goals for work are practical, focused on making a living and bringing in a paycheck. People who are not pursuing an upward career trajectory may experience a less intense crunch. However, the resulting economic stress due to lower wages and higher likelihood of periods of unemployment or underemployment could compound the crunch. What, then, does established adulthood look like for those in low-skilled jobsservers in restaurants, drivers of delivery trucks, clerks at checkout counters? These are among the questions to be investigated by researchers in established adulthood.

\section{Variation 5: Thriving and Arriving Versus Regret and Renovation}

Variations in development during established adulthood may be connected to choices made in the twenties. For example, work on "flourishing and floundering" in emerging adulthood suggests that some people may be better equipped than others to navigate the crunch in established adulthood (e.g., Nelson \& Padilla-Walker, 2013). Those who experienced events or made choices in their twenties that led to positive relationships, strong internalized values and identity, education or training credentials, a strong financial foundation, and hope for the future may find that their thirties are characterized by thriving and arriving (meeting future goals). For others, who experienced events or made choices in emerging adulthood that led to debt, broken relationships, a lack of education and direction, and, in some cases, addiction or a criminal record, may find that their thirties are characterized by regret and renovation (digging out of the past), making navigating the crunch more challenging. Consequently, it is critical to gain a better understanding of development during established adulthood by recognizing that development in the thirties and forties is a continuation of developmental processes that began earlier in life.

\section{Policy Prospects}

There is not enough space in this article to devote much to policy prescriptions, but given the prominence of the 
crunch in established adulthood it seems appropriate to discuss at least one policy response to it briefly. The most obvious policy to support established adults during the crunch is paid family leave and high-quality governmentsubsidized child care following the birth of a child. One study examined well-being in relation to parental status using data across 22 economically developed countries, including the United States, Canada, and a number of European countries (Glass et al., 2016). In most countries, being a parent was negatively related to well-being. However, in countries that provided the most social welfare benefits to parents, the relation was reversed, and being a parent was related to higher well-being. The United States had the fewest social welfare benefits for parents, and consequently had the largest parental "happiness penalty" of any country. Policies that support parenting may be especially important for people of color in the United States who are disproportionately engaged in precarious employment (Bureau of Labor Statistics, 2011, 2019b) and who may also be single parents (Hummer \& Hamilton, 2010).

Although paid parental leave is a welcome and necessary policy response to the crunch, it is no panacea. One concern is that it is nearly always the mother who takes the leave, across countries. If fathers take any leave at all, they do so for a shorter period than mothers do (OECD, 2018). Policy that favors leave for mothers may be partly in response to the fact that it is the mother who carried the child and gave birth and is thus likely to need a period of time to recover physically. However, such policies result in women's career trajectories flattening or falling to a greater extent than men's during the crunch years. This may especially be the case if they have more than one child. For these reasons, studies of the "motherhood wage penalty" have concluded that providing affordable child care is a more effective social welfare policy than paid parental leave in easing the crunch (Budig et al., 2016).

\section{Research Questions}

The worth of any theoretical idea should be measured in how much research it inspires. Many possible research questions can be generated by the idea of established adulthood. Here are a few examples.

1. How does the experience of established adulthood vary according to culture, race, ethnicity, and SES? The field of psychology in general has disproportionately focused on the experience of White, North American, college educated, affluent adults (Arnett, 2008). As such, it is imperative that researchers investigate the age period of 30-45 in different populations, especially populations that have been historically marginalized. To that end, important research questions are: does established adulthood in some form exist across cultures? How is established adulthood experienced by people of color in the United States and in other countries with racial disparities? How does social class influence the timing and intensity of developmental demands common to established adulthood? How do intersectional identities interact to shape established adulthood?

2. What developmental processes take place alongside central life tasks in established adulthood? Many of the features of established adulthood described above represent processes rather than static developmental outcomes. An important research question is how these processes unfold and influence one another as well as how they influence broader developmental trajectories. For example, how do romantic relationships impact an individual's identity and psychological functioning, and how do they connect to other developmental tasks relating to career progress or child care? Do established adults develop different coping skills, establish new forms of self-regulation, or pursue their developmental tasks in a different way than in other phases of adult life in order to manage the demands of the crunch? Similar questions around developmental processes can be asked for the other developmental features of established adulthood that we presented above.

3. What happens to the optimism of emerging adulthood once people reach established adulthood? It is well-known that emerging adulthood is a time when optimism is high. Nearly all emerging adults believe that they will attain the kind of life they envision, even if their current lives are not going well (Arnett, 2015). This vision typically includes all the elements of what eventually becomes the crunch: a rising career trajectory, an intimate partnership, and one or more children. Once they have reached established adulthood, how do people compare and reflect on their current lives in relation to what they had planned and hoped for as emerging adults? Do established adults in the midst of the crunch begin to regret occupational choices and/or family choices (e.g., choice of spouse, timing of marriage or childbearing)? If so, how do they respond to these regrets?

3. What is the degree and nature of stress in established adulthood? It will be important to follow emerging adults longitudinally as they enter established adulthood and see how their stress levels change as they take on the crunch. It is also important to explore the nature and degree of estab- 
lished adults' stress during this process, with qualitative research that goes beyond questionnaires. To what extent is stress engaging and fortifying, and at what point does it become unpleasant or overwhelming? Is there a stress-reward curve that is like the Yerkes-Dodson anxiety-performance curve, such that stress in established adulthood is rewarding up to a certain optimal level, then becomes aversive? Stress should also be compared among established adults who take diverse paths, for example, comparing those who experience the full crunch to those who remain single or coupled but without children.

4. How do relations with parents change? To what extent do established adults rely on their parents to help relieve the career-and-care-crunch? Are established adults who experience the crunch closer to their parents during these years than established adults who do not have children and thus have less need for their parents help, or does the necessity of reliance on parents more often breed ambivalence and resentment?

5. What becomes of friendships? How do friendships in established adulthood vary? Do established adults who experience the crunch have fewer friendships than other established adults, because they have less time, or just different friendships, that is, with other parents who have children of the same age?

6. What are the rewards and costs of diverse pathways through established adulthood? As noted, there are many possible routes through the years from Age 30 to 45. What do established adults say about the rewards and costs of each of these options, including their own? Do their perceptions depend on whether they have chosen their option or would have in fact preferred a different route?

\section{Conclusion}

In one sense, some form of established adulthood has always been a part of adult development, because in all societies most people have married, had children, and worked. However, a new conception of established adulthood is warranted because of how these roles are changing. Most adults have always had children, but in the past, bearing and caring for and providing for children dominated nearly all of adult life. The advent of emerging adulthood and a longer adult life span mean that today parenting is concentrated during the thirties and early forties, followed by several decades when the responsibilities of caring for children have waned. Nearly all adults have always worked, but only in recent decades have both men and women worked outside the home and had similar ambitions for career development. Responsibilities related to parenthood may collide with increased responsibilities at work as people climb the occupational ladder. This concentrates the career-and-care-crunch at Ages 30 to 45 and requires adult partners to engage in negotiation and compromise, frequently along with sacrifice and conflict.

We hope that our conceptualization of established adulthood and the crunch at the heart of it will promote new developmental research on a neglected age period. However, this idea has potential beyond the research arena. Understanding established adulthood as a distinct time of life has implications not only for people experiencing or about to experience the crunch, but also for therapists and other mental health professionals working with established adults. Additionally, understanding established adulthood as a unique developmental period with developmental antecedents and consequences can inform policymakers who have the power to promote programs that would alleviate the crunch and enhance the likelihood of the "thriving and arriving" outcome.

We have proposed the idea of established adulthood in this article with the goal of drawing attention to this fascinating and dynamic time of life and with the hope of inspiring increased investigation of its developmental norms and variations, including variations by race, ethnicity, social class, gender, and culture. There has been room in this article for only a sketch of a theory, and there is much to be filled in with further theorizing and research. The changes in the life tasks and responsibilities at Ages 30-45 in recent decades are likely to continue to evolve with societies' economic changes and continuing changes in family arrangements and gender roles. Researchers who investigate this developmental period are sure to have much to observe and explore in the decades to come.

\section{References}

American Psychological Association. (2007). Report of the APA Task Force on Socioeconomic Status. Washington, DC: Author. Retrieved from https://www.apa.org/pi/ses/resources/publications/task-force-2006 .pdf

Arnett, J. J. (2000). Emerging adulthood. A theory of development from the late teens through the twenties. American Psychologist, 55, 469480. http://dx.doi.org/10.1037/0003-066X.55.5.469

Arnett, J. J. (2008). The neglected 95\%: Why American psychology needs to become less American. American Psychologist, 63, 602-614. http:// dx.doi.org/10.1037/0003-066X.63.7.602

Arnett, J. J. (2015). Emerging adulthood: The winding road from the late teens through the twenties (2nd ed.). New York, NY: Oxford University Press. http://dx.doi.org/10.1093/oxfordhb/9780199795574.013.9

Arnett, J. J. (2016). Life stage concepts across history and cultures: Proposal for a new field on indigenous life stages. Human Development, 59, 290-316. http://dx.doi.org/10.1159/000453627 
Arnett, J. J. (2018). Happily stressed: The complexity of well-being in midlife. Journal of Adult Development, 25, 270-278. http://dx.doi.org/ 10.1007/s10804-018-9291-3

Baltes, P. B. (1987). Theoretical propositions of life-span developmental psychology: On the dynamics between growth and decline. Developmental Psychology, 23, 611-626. http://dx.doi.org/10.1037/0012-1649 .23.5.611

Bell, K. (2013). Constructions of "infertility" and some lived experiences of involuntary childlessness. Affilia: Journal of Women \& Social Work, 28, 284-295. http://dx.doi.org/10.1177/0886109913495726

Borelli, J., Nelson-Coffey, S., River, L., Birken, S., \& Moss-Racusin, C. (2017). Bringing work home: Gender and parenting correlates of workfamily guilt among parents of toddlers. Journal of Child \& Family Studies, 26, 1734-1745. http://dx.doi.org/10.1007/s10826-017-0693-9

Braveman, P., Egerter, S., \& Williams, D. R. (2011). The social determinants of health: Coming of age. Annual Review of Public Health, 32, 381-398. http://dx.doi.org/10.1146/annurev-publhealth-031210-101218

Brim, O. G., Ryff, C. D., \& Kessler, R. C. (Eds.). (2004). The MIDUS study: An overview. How healthy are we? A national study of wellbeing at midlife (pp. 1-34). Chicago, IL: The University of Chicago Press.

Bruner, M. W., Erickson, K., Wilson, B., \& Côté, J. (2010). An appraisal of athlete development models through citation network analysis. Psychology of Sport and Exercise, 11, 133-139. http://dx.doi.org/10.1016/ j.psychsport.2009.05.008

Budig, M. J., Misra, J., \& Boeckmann, I. (2016). Work-family policy trade-offs for mothers? Unpacking the cross-national variation in motherhood earnings penalties. Work and Occupations, 43, 119-177. http:// dx.doi.org/10.1177/0730888415615385

Bureau of Labor Statistics. (2011). Earnings and employment by occupation, race, ethnicity, and sex, 2010. Retrieved from https://www.bls.gov/ opub/ted/2011/ted_20110914.htm

Bureau of Labor Statistics. (2019a). Median years of tenure with current employer for employed wage and salary workers by age and sex, selected years, 2008-2018. Retrieved from https://www.bls.gov/news .release/tenure.t01.htm

Bureau of Labor Statistics. (2019b). Labor force characteristics by race and ethnicity, 2018. Retrieved from https://www.bls.gov/opub/reports/raceand-ethnicity/2018/home.htm

Cherlin, A. J. (2010). The marriage-go-round: The state of marriage and the family in America today. New York, NY: Vintage.

Chi, M. T., Glaser, R., \& Farr, M. J. (Eds.). (2014). The nature of expertise. New York, NY: Psychology Press. http://dx.doi.org/10.4324/ 9781315799681

Cotter, D., \& Pepin, J. A. (2017). Trending toward traditionalism? Changes in youths' gender ideology. Online symposium, Council on Contemporary Families. Retrieved from https://contemporaryfamilies .org/2-pepin-cotter-traditionalism/

Cranney, S., \& Miles, A. (2017). Desperate housewives? Differences in work satisfaction between stay-at-home and employed mothers, 19722012. Journal of Family Issues, 38, 1604-1625. http://dx.doi.org/10 $.1177 / 0192513 X 16663253$

Cukrowska-Torzewska, E. (2017). Cross-country evidence on motherhood employment and wage gaps: The role of work-family policies and their interaction. Social Politics, 24, 178-220. http://dx.doi.org/10.1093/sp/ jxx004

Day, D. V., Harrison, M. M., \& Halpin, S. M. (2012). An integrative approach to leader development: Connecting adult development, identity, and expertise. New York, NY: Routledge. http://dx.doi.org/10 $.4324 / 9780203809525$

DeLyser, G. (2012). At midlife, intentionally childfree women and their experiences of regret. Clinical Social Work Journal, 40, 66-74. https:// doi-org.ezproxyemc.flo.org/10.1007/s10615-011-0337-2
DePaulo, B. (2006). Singled out: How singles are stereotyped, stigmatized, and ignored, and still live happily ever after. New York, NY: St. Martin's Press.

DePaulo, B. M. (2012). Single people. New York, NY: Oxford University Press.

Dew, J., \& Wilcox, W. B. (2011). If momma ain't happy: Explaining declines in marital satisfaction among new mothers. Journal of Marriage and Family, 73, 1-12. http://dx.doi.org/10.1111/j.1741-3737.2010 .00782.x

Doede, M. S. (2016). Black jobs matter: Racial inequalities in conditions of employment and subsequent health outcomes. Public Health Nursing, 33, 151-158. http://dx.doi.org/10.1111/phn.12241

Doyle, J., Pooley, J. A., \& Breen, L. (2013). A phenomenological exploration of the childfree choice in a sample of Australian women. Journal of Health Psychology, 18, 397-407. http://dx.doi.org/10.1177/ 1359105312444647

Elder, G. H., Jr., \& Shanahan, M. J. (2006). The life course and human development. In W. Damon \& R. M. Lerner (Eds.), Handbook of child psychology (Vol. 1, pp. 665-715). New York, NY: Wiley.

England, P., Bearak, J., Budig, M. J., \& Hodges, M. J. (2016). Do highly paid, highly skilled women experience the largest motherhood penalty? American Sociological Review, 81, 1161-1189. http://dx.doi.org/10 $.1177 / 0003122416673598$

Fillo, J., Simpson, J. A., Rholes, W. S., \& Kohn, J. L. (2015). Dads doing diapers: Individual and relational outcomes associated with the division of childcare across the transition to parenthood. Journal of Personality and Social Psychology, 108, 298-316. http://dx.doi.org/10.1037/ a0038572.supp

Fletcher, G. J., Simpson, J. A., Campbell, L., \& Overall, N. C. (2015). Pair-bonding, romantic love, and evolution: The curious case of Homo sapiens. Perspectives on Psychological Science, 10, 20-36. http://dx.doi .org/10.1177/1745691614561683

Garrett-Peters, R., \& Burton, L. M. (2016). Tenuous ties: The nature and costs of kin support among low-income rural black mothers. Women, Gender, and Families of Color, 4, 4-35. http://dx.doi.org/10.5406/ womgenfamcol.4.1.0004

Glass, J., Simon, R. W., \& Andersson, M. A. (2016). Parenthood and happiness: Effects of work-family reconciliation policies in 22 OECD countries. American Journal of Sociology, 122, 886-929. http://dx.doi .org/10.1086/688892

Goldberg, A. E. (2010). The transition to adoptive parenthood. In T. W. Miller (Ed.), Handbook of stressful transitions across the lifespan (pp. 165-184). New York, NY: Springer Science + Business Media. http:// dx.doi.org/10.1007/978-1-4419-0748-6_9

Goldberg, S. K., \& Conron, K. J. (2018). How many same-sex couples in the U.S. are raising children? Retrieved from the Williams Institute website williamsinstitute.law.ucla.edu/research/parenting/how-manysame-sex-parents-in-us/

Gottman, J. M. (2014). What predicts divorce?: The relationship between marital processes and marital outcomes. New York, NY: Psychology Press. http://dx.doi.org/10.4324/9781315806808

Gottman, J., \& Gottman, J. (2017). The natural principles of love. Journal of Family Theory \& Review, 9, 7-26. http://dx.doi.org/10.1111/jftr .12182

Havighurst, R. J. (1953). Human development and education. Oxford, UK: Longmans, Green.

Hoare, C. (Ed.). (2006). Growing a discipline at the borders of thought. Handbook of adult development and learning: A handbook of theory, research, and practice (pp. 3-26). Oxford, UK: Oxford University Press.

Hooker, K. (2015). Towards a new synthesis for development in adulthood. Research in Human Development, 12, 229-236. http://dx.doi.org/10 $.1080 / 15427609.2015 .1068036$

Houglum, P. A. (2010). Therapeutic exercise for musculoskeletal injuries. Champaign, IL: Human Kinetics. 
Hu, W., Shi, Q. Z., Han, Q., Wang, X., \& Adey, P. (2010). Creative scientific problem finding and its developmental trend. Creativity Research Journal, 22, 46-52. http://dx.doi.org/10.1080/1040041090 3579551

Hudson, V. M., \& Den Boer, A. (2002). A surplus of men, a deficit of peace: Security and sex ratios in Asia's largest states. International Security, 26, 5-38. http://dx.doi.org/10.1162/016228802753696753

Huffman, A. S., Culbertson, S. B., Henning, J., \& Goh, A. (2013). Workfamily conflict across the lifespan. Journal of Managerial Psychology, 28, 761-780. http://dx.doi.org/10.1108/JMP-07-2013-0220

Hummer, R. A., \& Hamilton, E. R. (2010). Race and ethnicity in fragile families. The Future of Children, 20, 113-131. http://dx.doi.org/10 .1353 /foc. 2010.0003

Huston, T. L., Caughlin, J. P., Houts, R. M., Smith, S. E., \& George, L. J. (2001). The connubial crucible: Newlywed years as predictors of marital delight, distress, and divorce. Journal of Personality and Social Psychology, 237-252. http://dx.doi.org/10.1037/0022-3514.80.2.237

Hymowitz, K., Carroll, J. S., Wilcox, W. B., \& Kaye, K. (2013). Knot yet: The benefits and costs of delayed marriage in America. Charlottesville, VA: National Marriage Project.

Jensen, L. A. (Ed.). (2015). Cultural-developmental scholarship for a global world: An introduction. The Oxford handbook of human development and culture: An interdisciplinary perspective (pp. 3-13). New York, NY: Oxford University Press. http://dx.doi.org/10.1093/oxfordhb/ 9780199948550.001.0001

Knecht, M., \& Freund, A. M. (2016). Boundary management: A timesampling study on managing work and private life in middle adulthood. Research in Human Development, 13, 297-311. http://dx.doi.org/10 .1080/15427609.2016.1234307

Koert, E., \& Daniluk, J. C. (2017). When time runs out: Reconciling permanent childlessness after delayed childbearing. Journal of Reproductive and Infant Psychology, 35, 342-352. http://dx.doi.org/10.1080/ 02646838.2017.1320363

Kossek, E. E., Lautsch, B. A., \& Eaton, S. C. (2006). Telecommuting, control, and boundary management: Correlates of policy use and practice, job control, and work-family effectiveness. Journal of Vocational Behavior, 68, 347-367. http://dx.doi.org/10.1016/j.jvb.2005.07.002

Kunkel, S. R., Brown, J. S., \& Whittington, F. J. (2014). Global aging: Comparative perspectives on aging and the life course. New York, NY: Springer. http://dx.doi.org/10.1891/9780826105479

Lachman, M. E. (2004). Development in midlife. Annual Review of Psychology, 55, 305-331. http://dx.doi.org/10.1146/annurev.psych.55 .090902 .141521

Lachman, M. E., Teshale, S., \& Agrigoroaei, S. (2015). Midlife as a pivotal period in the life course: Balancing growth and decline at the crossroads of youth and old age. International Journal of Behavioral Development, 39, 20-31. http://dx.doi.org/10.1177/0165025414533223

Le, Y., McDaniel, B. T., Leavitt, C. E., \& Feinberg, M. E. (2016). Longitudinal associations between relationship quality and coparenting across the transition to parenthood: A dyadic perspective. Journal of Family Psychology, 30, 918-926. http://dx.doi.org/10.1037/ fam0000217

Levinson, D., Darrow, C., Klein, E., Levinson, M., \& McKee, B. (1978). The seasons of a man's life. New York, NY: Knopf.

Mathews, T. J., \& Hamilton, B. E. (2016). Mean age of mothers is on the rise: United States, 2000-2014 (NCHS Data Brief, No. 232). Hyattsville, MD: National Center for Health Statistics.

Mednick, S. A. (1963). Research creativity in psychology graduate students. Journal of Consulting Psychology, 27, 265-266.

Mickelson, K. D., \& Biehle, S. N. (2017). Gender and the transition to parenthood: Introduction to the special issue. Sex Roles, 76, 271-275. http://dx.doi.org/10.1007/s11199-016-0724-9

Nazarinia-Roy, R., Schumm, W. R., \& Britt, S. L. (2014). Transition to parenthood. New York, NY: Springer Science + Business Media.
Nelson, L. J., \& Chen, X. (2007). Emerging adulthood in China: The role of social and cultural factors. Child Development Perspectives, 1, 8691.

Nelson, L. J., \& Padilla-Walker, L. M. (2013). Flourishing and floundering in emerging-adult college students. Emerging Adulthood, 1, 67-78.

Nelson, S. K., Kushlev, K., \& Lyubomirsky, S. (2014). The pains and pleasures of parenting: When, why, and how is parenthood associated with more or less well-being? Psychological Bulletin, 140, 846.

Organisation for Economic Co-operation and Development. (2018). Trends in parental leave policies since 1970. Retrieved from http://www .oecd.org/els/family/PF2_5_Trends_in_leave_entitlements_around_child birth.pdf

Organisation for Economic Co-operation and Development Family Database. (2018). Share of births outside of marriage. Retrieved from http:// www.oecd.org/els/family/SF_2_4_Share_births_outside_marriage.pdf

Organisation for Economic Co-operation and Development. (2019a). Age of mothers at childbirth and age-specific fertility. Retrieved from http:// www.oecd.org/els/family/database.htm

Organisation for Economic Co-operation and Development. (2019b). Employment profiles over the life course. Retrieved from https://www.oecd .org/els/soc/LMF_1_4_Employment_profiles_over_life_course.pdf

Organisation for Economic Co-operation and Development. (2019c). Marriage and divorce rates. Retrieved from https://www.oecd.org/els/family/ SF_3_1_Marriage_and_divorce_rates.pdf

Organisation for Economic Co-operation and Development. (2019d). Measuring women's economic empowerment: Time use data and gender inequality. OECD Development Policy Papers. Retrieved from http:// www.oecd.org/dev/development-gender/MEASURING-WOMENSECONOMIC-EMPOWERMENT-Gender-Policy-Paper-No-16.pdf

Peitilainen, K. H., Kaprio, J., Borg, P., Plasqui, G., Yki-Järvinen, H., Kujala, U. M., \& Rissanen, A. (2008). Physical inactivity and obesity: A vicious circle. Obesity, 16, 409-414.

Pelton, S., \& Hertlein, K. (2011). A proposed life cycle for voluntary childfree couples. Journal of Feminist Family Therapy, 23, 39-53. http://dx.doi.org/10.1080/08952833.2011.548703

Perlmutter, M., Kaplan, M., \& Nyquist, L. (1990). Development of adaptive competence in adulthood. Human Development, 33, 185-197.

Riediger, M., Freund, A. M., \& Baltes, P. B. (2005). Managing life through personal goals: Intergoal facilitation and intensity of goal pursuit in younger and older adulthood. Journals of Gerontology Series B: Psychological Sciences \& Social Sciences, 60, 84-91. http://dx.doi.org/10 .1093/geronb/60.2.p84

Riza, S. D., Ganzach, Y., \& Liu, Y. (2018). Time and job satisfaction: A longitudinal study of the differential roles of age and tenure. Journal of Management, 44, 2558-2579.

Rosenberger, N. (2007). Rethinking emerging adulthood in Japan: Perspectives from long-term single women. Child Development Perspectives, 1 , 92-95.

Ryff, C. D., Kitayam, S., Karasawa, M., Markus, H., Kawakami, N., \& Coe, C. (2008). Survey of Midlife in Japan April-September, 2008 (ICPSR Report No. 30822). Retrieved from https://www.icpsr.umich .edu/icpsrweb/ICPSR/studies/30822/summary

Schaie, K. W. (2013). Developmental influences on adult intelligence: The Seattle Longitudinal Study (2nd ed.). New York, NY: Oxford University Press.

Sheedy, A., \& Gambrel, L. E. (2019). Coparenting negotiation during the transition to parenthood: A qualitative study of couples' experiences as new parents. American Journal of Family Therapy, 47, 67-86. https:// doi-org.ezproxyemc.flo.org/10.1080/01926187.2019.1586593

Sherman, J. (2009). Bend to avoid breaking: Job loss, gender norms, and family stability in rural America. Social Problems, 56, 599-620. http:// dx.doi.org/10.1525/sp.2009.56.4.599 
Simonton, D. K. (2010). Creativity in highly eminent individuals. The Cambridge handbook of creativity (pp. 174-188). New York, NY: Cambridge University Press.

Sternberg, R. J. (2018). A triangular theory of creativity. Psychology of Aesthetics, Creativity, and the Arts, 12, 50-67. http://dx.doi.org/10 .1037/aca0000095

Taylor, Z. E., \& Conger, R. D. (2017). Promoting strengths and resilience in single-mother families. Child Development, 88, 350-358.

United States Department of Labor. (2019). Number of Jobs, Labor Market Experience, and Earnings Growth: Results from a National Longitudinal Survey Summary. Retrieved from https://www.bls.gov/news.release/ nlsoy.nr0.htm

Wang, W. (2019, June 4). The happiness penalty for breadwinning moms. [Web log post]. Retrieved from https://ifstudies.org/blog/the-happinesspenalty-for-breadwinning-moms
Wayne, J. H., Butts, M. M., Casper, W. J., \& Allen, T. D. (2017). In search of balance: A conceptual and empirical integration of multiple meanings of work-family balance. Personnel Psychology, 70, 167-210.

Yamada, M. (2017). Can we overcome the obstacles of marriage through romantic love? Annals of Family Studies, 41, 35-39.

Young, C., Roberts, R., \& Ward, L. (2019). Application of resilience theories in the transition to parenthood: A scoping review. Journal of Reproductive and Infant Psychology, 37, 139-160. http://dx.doi.org/10 .1080/02646838.2018.1540860

Received June 17, 2019

Revision received December 12, 2019

Accepted December 21, 2019 